
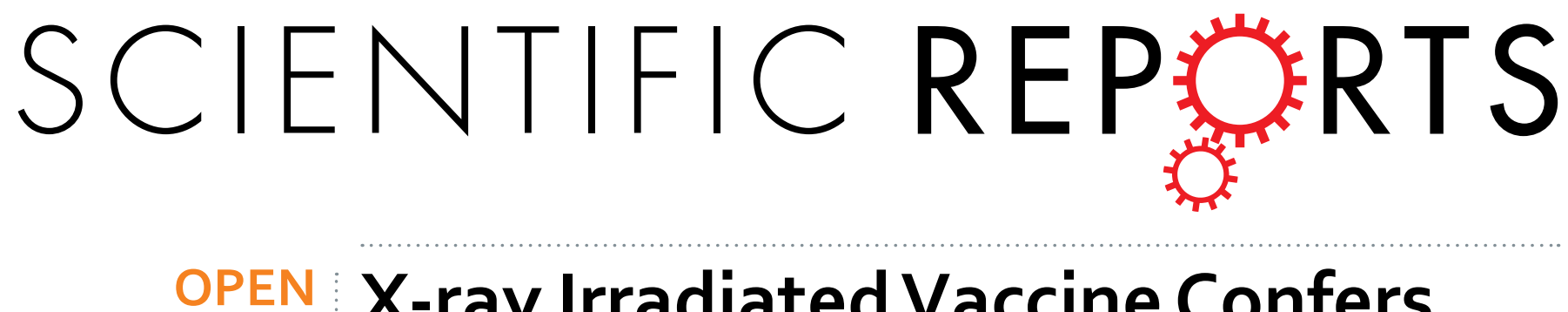

\title{
X-ray Irradiated Vaccine Confers protection against Pneumonia caused by Pseudomonas Aeruginosa
}

Received: 24 April 2015

Accepted: 24 November 2015

Published: 16 February 2016
Yanyan $\mathrm{Li}^{1,2,{ }^{*}}$, Zhenling Wang ${ }^{2,{ }^{*}}$, Xiaoxiao Liu ${ }^{2,{ }^{*}}$, Jianying Tang ${ }^{2}$, Bin Peng ${ }^{2,3}$ \& Yuquan Wei ${ }^{2}$

Pseudomonas aeruginosa is a gram-negative bacterium and one of the leading causes of nosocomial infection worldwide, however, no effective vaccine is currently available in the market. Here, we demonstrate that inactivation of the bacteria by X-ray irradiation inhibits its replication capability but retained antigenic expression functionally thus allowing its use as a potential vaccine. Mice immunized by this vaccine were challenged by the parental strain, the O-antigen-homologous strain PAO-1 (O2/O5) and heterologous strain PAO-6 $(\mathrm{O} 6)$ in an acute pneumonia model. We further measured the protective effect of the vaccine, as well as host innate and cellular immunity responses. We found immunized mice could protect against both strains. Notably, the antiserum only had significant protective role against similar bacteria, while adoptive transfer of lymphocytes significantly controlled the spread of the virulent heterologous serogroup PAO- 6 infection, and the protective role could be reversed by CD4 rather than CD8 antibody. We further revealed that vaccinated mice could rapidly recruit neutrophils to the airways early after intranasal challenge by PAO-6, and the irradiated vaccine was proved to be protective by the generated $\mathrm{CD} 4^{+} \mathrm{IL}-17^{+}$Th17 cells. In conclusion, the generation of inactivated but metabolically active microbes is a promising strategy for safely vaccinating against Pseudomonas aeruginosa.

Pseudomonas aeruginosa (P. aeruginosa) is an opportunistic pathogen and one of the leading nosocomial infections worldwide. It is often the primary agent infecting immune compromised patients who suffer from severe burns, cancer or who is undergoing immunosuppressive therapies ${ }^{1,2}$. Despite considerable advances in the development of antimicrobial and supportive therapy, effective control or treatment strategy of $P$. aeruginosa invasion remains a persistent headache. Several studies have demonstrated the natural resistance of $P$. aeruginosa to antibiotics ${ }^{3}$ or its ability to evade the host's immune system ${ }^{4,5}$. These characteristics give rise to the difficulties in treating $P$. aeruginosa infection, resulting in a desire to pursue immunotherapeutic approach to counter this persistent pathogen.

Several vaccine candidates have been investigated. They include sub-cellular antigens like structural components such as flagella, pili, outer membrane proteins or lipopolysaccharides (LPS), ormucoid exopolysaccharides (MEP), exotoxin A and proteases ${ }^{6-8}$. These vaccine candidates have been tested in phase I-III clinical trials ${ }^{9-11}$. However, despite intense efforts over the past few decades, vaccines against $P$. aeruginosa experienced little success, a safe and effective vaccine is not available currently ${ }^{8}$. In our approach, we intend to simultaneously target multiple antigens of $\mathrm{P}$. aeruginosa with a non-replicating but metabolically active vaccine by inducing effective polyclonal antibodies.

As vaccine candidates, heat or formalin killed pathogens are safe but they usually elicit a weaker immunogenic response due to impaired antigenic structure ${ }^{12}$. In contrast, live vaccines may have enhanced immunogenicity and increased durability in the host, but they usually cause safety problems, particularly among the immune-compromised patients ${ }^{13}$. Fortunately, this dilemma in vaccine research is partly resolved by the recently developed approach of photochemical or irradiation inactivated vaccines ${ }^{14}$. The use of ionizing radiation has been explored in the development of vaccines for the prevention of some infectious diseases in cattle and humans the past few years ${ }^{15-18}$. This strategy allowed the completely non proliferated pathogen to present the immunologically functional epitopes, and they activate a robust immune response which is comparable to that induced by a live and unprocessed pathogen.

${ }^{1}$ Department of Radiation Oncology, Fudan University Shanghai Cancer Center, Fudan University, Shanghai, China. ${ }^{2}$ State Key Labortary of Biotherapy and Cancer Center, West China Hospital, Sichuan University, and Collaborative Innovation Center of Biotherapy, Cheng Du, China. ${ }^{3}$ Department of Oncology, Third Xiangya Hospital, Central South University, Changsha, China. ${ }^{*}$ These authors contributed equally to this work. Correspondence and requests for materials should be addressed toY.W. (email: yqwei@scu.edu.cn) 
(A)

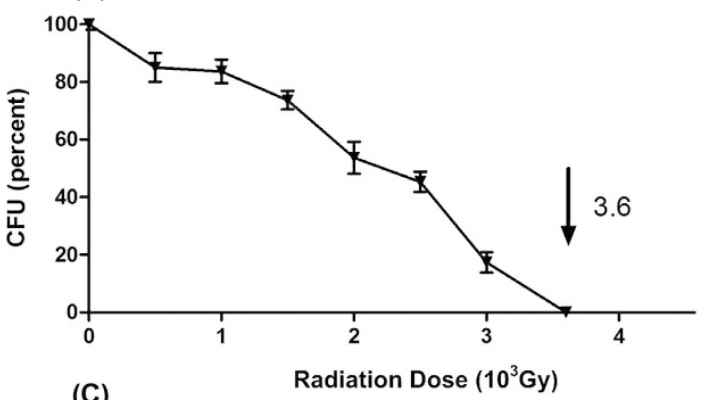

(C)

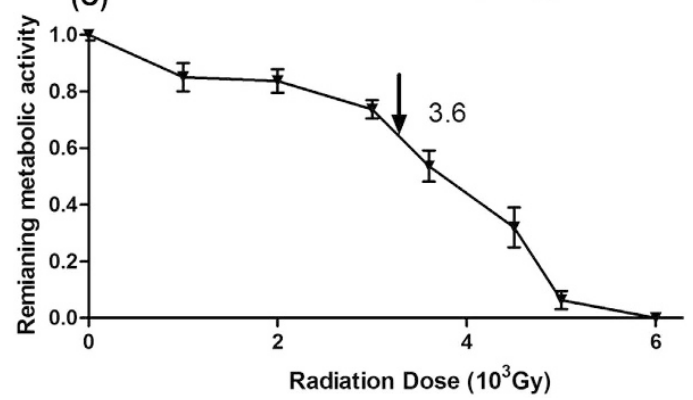

(B)

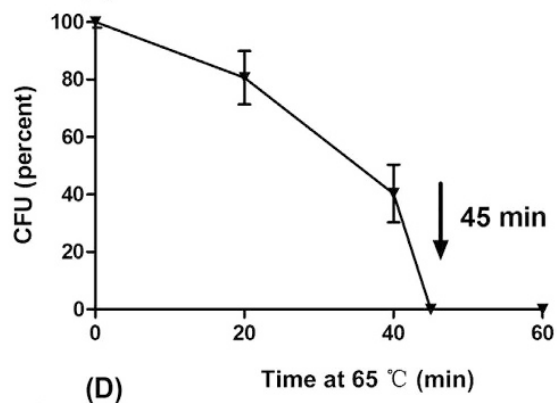

(D)

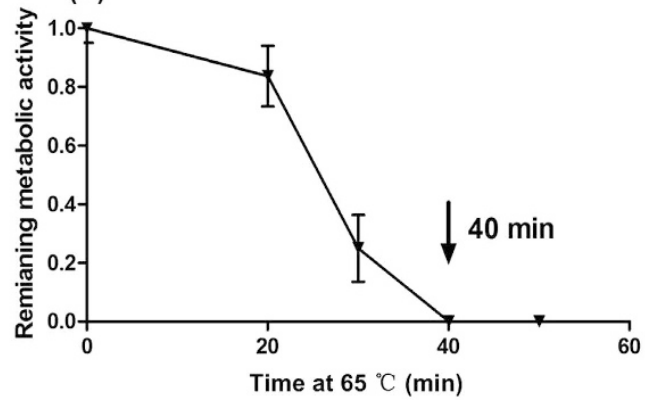

Figure 1. Irradiation inhibits $P$. aeruginosa reproductive viability but does not impair metabolic activity. Increased exposure time to $\mathrm{X}$-ray irradiation or heat $\left(65^{\circ} \mathrm{C}\right)$ resulted in decreased reproductive viability $(\mathbf{A}, \mathbf{B})$ and metabolic activity (C,D) of ATCC 27853 cells. Bacterial viability was determined by counting CFUs on agar plates, and metabolic activity was measured by monitoring the OD using Alamar Blue colorimetric assay. $\mathrm{X}$ ray irradiation diminished ATCC 27853 reproductive viability but does not impair its metabolic activity. The arrow denotes the irradiation dose, which could reduce the reproductive viability to $0 \%$ while retained $63.33 \% \pm 4.49 \%$ metabolic activity compared with the live cells $(\mathbf{C})$. Results represent three independent experiments and are expressed as mean $\pm S D(n=5)$.

In this study, we demonstrate that inactivation of $P$. aeruginosa by X-ray irradiation inhibited its replication capability while retained the metabolic viability. The immunization increased survival condition of $P$. aeruginosa pneumonia suffers, and the protective role may mainly realized by $\mathrm{T}$ lymphocytes rather than serum antibody against heterologous serogroup infection, while both T lymphocytes and serum worked against the infection of homologous serogroup P. aeruginosa. The protective effect of the vaccine is further demonstrated to be mainly mediated by $\mathrm{CD} 4^{+} \mathrm{T}$ lymphocytes, and predominantly realized by $\mathrm{CD} 4^{+} \mathrm{IL}-17^{+} \mathrm{Th} 17$ cells. These observations may provide a new vaccine preparation strategy for active immunotherapy and potential targeted therapy for $P$. aeruginosa.

\section{Results}

Preparation and safety evaluation of $\mathbf{X}$ ray irradiated vaccine. Aliquots of $P$. aeruginosa ATCC 27853 were exposed to escalating X-ray irradiation or heat $\left(65^{\circ} \mathrm{C}\right)$, and the CFUs present from each aliquot were determined by plating on LB agar. As shown in Fig. 1A, an expected decrease in viability was detected with increasing heat duration or irradiation doses. A complete loss of replication viability of the bacteria was observed at a minimum dose of $3600 \mathrm{~Gy}$, and the 45 min's incubation at $65^{\circ} \mathrm{C}$ inactivated the bacteria (Fig. 1). Likewise, the metabolic activity is also affected with heat or irradiation treatment. Of note, X-ray irradiation retained considerable metabolic activity of the inactivated bacteria, as indicated by the ability of irradiated ATCC 27853 to convert Alamar blue dye from blue to pink color. Metabolic activity of ATCC 27853 decreased as X-ray dosage increased, and the specific activity was $63.33 \% \pm 4.49 \%$ when exposed to $3600 \mathrm{~Gy}$ compared to that of the active live bacteria (100\%). In contrast, heat-killed ATCC 27853 failed to cause the color change, which showed a complete loss of metabolic activity (Fig. 1). We then tested the in vivo proliferative activity of the irradiated bacteria, C57BL/6 mice were inoculated with $5 \times 10^{9} \mathrm{CFU}$ (intra-peritoneally, intra-nasally and subcutaneously) equivalent of either heatkilled $\left(65^{\circ} \mathrm{C}\right.$ for $\left.45 \mathrm{~min}\right)$ or irradiation inactivated P. aeruginos $a$, and no bacteria were detected in the main organs and blood of mice at one, three and five days post inoculation in both groups. We finally exposed the ATCC 27853 bacteria to $3600 \mathrm{~Gy} \mathrm{X}$-ray irradiation to manufacture an active but non-replicative whole cell vaccine.

We further immunized the mice with high dose vaccine $\left(10^{8} \mathrm{CFUs}\right)$ weekly by different routes, including subcutaneous, intra-nasal and intra-peritoneal method, and studied the potential long-term toxicity of the vaccine. We observed no adverse consequences in gross measures such as weight loss (Table S1.) or hematologic toxicities (Table S2, S3.). The immunized mice only exhibited purulent presentation at the injection site by the subcutaneous route, and had no clinical signs of weight loss, lethargy, piloerection, tremors, periorbital exudates, respiratory distress, or diarrhea. Furthermore, we investigated the pathologic changes of the immunized mice. One week after the fourth immunization, the immunized C57BL/6 mice, and unimmunized controls were all sacrificed, the main organ samples were taken out and applied for H\&E staining to investigate the microscopic changes. The toxic 
(A)

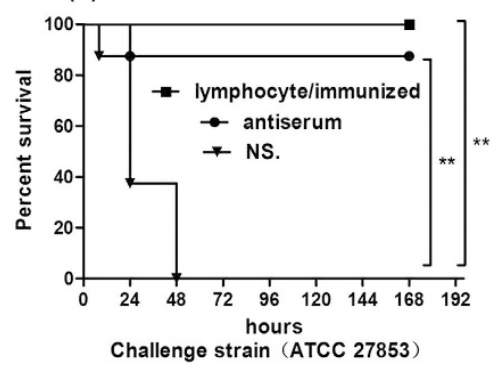

(B)

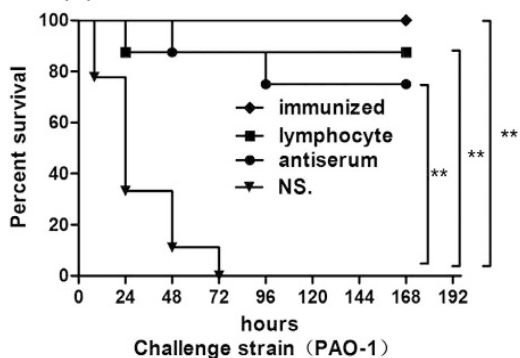

(C)

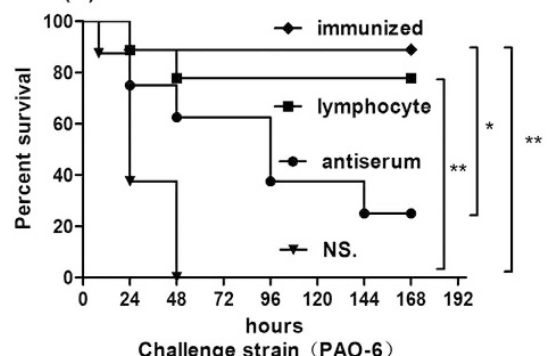

Figure 2. Evaluation of the vaccine induced protection against $P$. aeruginosa pneumonia in vivo. Immunized C57BL/ 6 mice received escalating doses of $10^{8}, 5 \times 10^{8}, 10^{9}$, and $5 \times 10^{9} \mathrm{CFUs}$ irradiated ATCC27853 cells intra-nasally every week. $1 \times 10^{7}$ spleen lymphocytes or $300 \mu \mathrm{l}$ serum were isolated from the immunized mice and transferred to normal mice $12 \mathrm{~h}$ before and after challenge, while controls received normal saline. Kaplan-Meier curves were plotted for mice of the above groups which were challenged by $5 \times 10^{6} \mathrm{CFUs}$ the parental strain ATCC 27853 (A), $5 \times 10^{6} \mathrm{CFU}$ somologous serotype PAO-1(B) and $1 \times 10^{7} \mathrm{CFUs}$ heterologous serotype PAO-6 (C), and monitored the seven days survival rates. Irradiated vaccine protected mice against intranasal challenge by virulent $P$. aeruginosa, serum transferred mice showed powerful anti-infectious effect against homologous strain (ATCC 27853 and PAO-1) while T lymphocytes adopter mice survived longer when challenged by the homologous and heterologous serotype strains (ATCC 27853, PAO-1, and PAO-6) than the controls. Results represent three independent experiments $\left(\mathrm{n}=10,{ }^{*} \mathrm{p}<0.05,{ }^{* *} \mathrm{p}<0.01\right)$.

pathologic changes in heart, liver, spleen, lung, and kidney were not detected by microscopic examination (data not shown). These results demonstrated that the vaccine did not cause obvious systemic toxicity.

Protective efficacy of X-ray irradiated $P$. aeruginosa vaccination in vivo. We immunized mice by intra-nasal injection of irradiated vaccine or saline (unimmunized mice) once a week for four weeks, and then challenged the mice with $P$. aeruginosa strains. We found that the vaccine has significant protective effect against lethality in homologous serogroup PAO-1 (O2/O5) $(\mathrm{p}<0.01)$ (Fig. 2A), the parent strain ATCC $27853(\mathrm{O} 2 /$ O5) $(\mathrm{p}<0.01)$ (Fig. 2B) and heterologous serogroup PAO-6 bacteria (O6) $(\mathrm{p}<0.01)$ (Fig. 2C), when compared with the controls after challenged by a relative high dose (five times of lethal dose 50) of the active live strains. Specifically, immunization lead to $100 \%$ protective effect in homologous serogroup compared with $87.5 \%$ in the heterologous serogroup PAO-6 challenge.

We further isolated sera and spleen lymphocytes from immunized mice and transferred them to the normal mice. Protective results were shown when mice that received spleen lymphocytes were challenged with the above three bacteria strains. However, the transferred sera only showed protective role for homologous serogroup PAO-1/ ATCC 27853 infection $(\mathrm{p}<0.01)$, and there was no significant protection after challenged by the heterologous serogroup PAO-6 ( $p>0.05$ ); only $22.5 \%$ anti-serum transferred mice survived seven days when infected by PAO- 6 cells compared with $87.5 \%$ survival rate of the immunized group (Fig. 2).

Opsonic killing activity of sera against $P$. aeruginosa in vitro. The opsonic killing ability of anti-sera isolated from immunized mice were similar for either ATCC 27853 or PAO-1cells, and were about twice more effective than the activity of serum from unimmunized mice. The anti-serum demonstreated more effective killing ability against the homologous $\mathrm{O} 2 / \mathrm{O} 5$ than the heterologous $\mathrm{O} 6$ strain bacterial cells $(\mathrm{p}<0.05)$, and the immunized antiserum only has a tendency of proliferation inhibition to PAO- 6 cells. As depicted in Fig. 3, there was minimal opsonic killing ability of strain ATCC $27853(28.67 \pm 2.51 \%)$ and PAO-1 $(27.37 \pm 3.17 \%)$ in the unimmunized mice serum, whereas effective killing was achieved by sera from immunized mice against the LPS-homologous ATCC $27853(80.8 \% \pm 2.02 \%)$ and PAO-1 cells $(81.78 \% \pm 3.24 \%)$. Surprisingly, although the replication of PAO- 6 bacteria was not inhibited with the presence of anti-sera isolated from the immunized mice, there was a significantly higher killing ability when compared with that of serum isolated from control group mice $(\mathrm{p}<0.05)$. All these results demonstrated that antibody is effective against homologous serotype $P$. aeruginosa cells proliferation, but only has partial protective role in heterologous serotype $P$. aeruginosa infection, which is in accordance with the survival protective results in vivo.

$\mathrm{CD4}^{+}$T lymphocytes response elicited by vaccine in vitro and in vivo. We isolated spleen $\mathrm{T}$ lymphocytes from immunized mice and co-cultured them with irradiated splenocytes as antigen presenting cells (APCs), heat-killed $P$. aeruginosa cells as antigens and measured T lymphocytes proliferation by CCK- 8 test at $24 \mathrm{~h}$ and $72 \mathrm{~h}$. As shown in Fig. 4, there was a higher proliferation level of immunized T cells to either ATCC 27853, PAO-1 or PAO-6 at both $24 \mathrm{~h}$ (Fig. $4 \mathrm{~A}$ ) and $72 \mathrm{~h}$ (Fig. 4B) when compared with those of T lymphocytes isolated from the controls $(\mathrm{p}<0.05)$, which means vaccinated $\mathrm{T}$ lymphocytes could be stimulated by $P$. aeruginosa strains regardless of LPS serotypes. Besides, proliferation of the irradiated vaccine immune T lymphocytes was significantly inhibited by antibody to CD4 but not to CD8.

In order to further distinguish whether $\mathrm{CD} 4^{+} \mathrm{T}$ lymphocytes were the only immune cells involved in the anti-infection effect by X-ray irradiated vaccine in vivo, $\mathrm{CD} 4^{+}$or $\mathrm{CD} 8^{+} \mathrm{T}$ lymphocytes were depleted independently by corresponding antibodies as described above. We found that in vivo depletion of $\mathrm{CD} 4^{+} \mathrm{T}$ lymphocytes could 


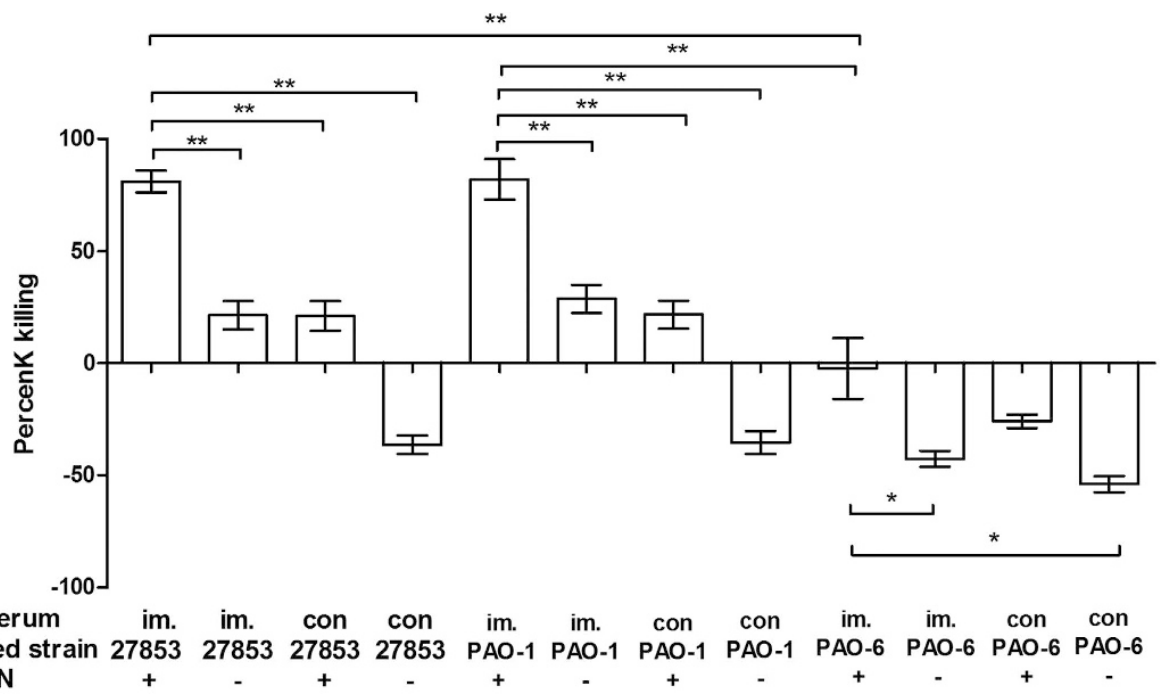

Figure 3. Opsonic killing activity elicited by the serum isolated from immunized mice against vaccine homologous strains (ATCC 27853, PAO-1) and vaccine heterologous strain (PAO-6) cells. Immunized group contained serum isolated from immunized mice, $1 \times 10^{6} \mathrm{PMN}$ and $10^{5} \mathrm{CFUs}$ heat-killed $P$. aeruginos $a$ cells, while negative control group contained sera without PMNs. Serum isolated from immunized mice has higher killing activity against homologous strain (ATCC 27853 and PAO-1) cells than that of the controls (serum isolated from unimmunized mice). Results represent three independent experiments and are expressed as mean $\pm \mathrm{SD}\left(\mathrm{n}=5\right.$, ANOVA, $\left.{ }^{\star} \mathrm{p}<0.05,{ }^{* *} \mathrm{p}<0.01\right)$.

completely abrogate the anti-infectious activity with the immunization. In the group of vaccine immunized group, the survival rate decreased to $37.5 \%, 37.5 \%$, and $12.5 \%$ after depletion of $\mathrm{CD} 4^{+} \mathrm{T}$ lymphocytes when challenged with the strain ATCC27853, PAO-1, and PAO-6, respectively (Fig. 4). Furthermore, the survival rate was not decreased compared to the control group when challenged by ATCC 27853 (Fig. 4C), PAO-1 (Fig. 4D), since there existed effective killing ability of anti-serum against homologous serotype O2/O5. Depletion of $\mathrm{CD} 8^{+} \mathrm{T}$ lymphocytes showed that there was no relationship between $\mathrm{CD} 8^{+} \mathrm{T}$ lymphocytes and the anti-infectious effect. In addition, the treatment with normal rat IgG showed no improvement of the survival rate.

Neutrophils recruitment induced by vaccination. Bacteria load is closely related with the survival status of infectious disease, so we test the bacteria number of the immunized mice post challenge to investigate the mechanisms involved in this protective effect of the vaccine against heterologous strain PAO-6 infection. It was interesting to note that the number of PAO- 6 cells in the main organs and blood were decreasing within the seven days, and the mice finally clearly the spread of PAO-6 cells (Fig. 5). However, the control group mice almost died within twenty-four hours, and the corresponding bacteria number could not be detected.

When it comes to the CFUs in the lung tissue and blood of the PAO- 6 infected mice early (at $6 \mathrm{~h}$ and $18 \mathrm{~h}$ ) after challenge, as expected, the immunization resulted in the reduction of lung and blood bacterial load in comparison with that of the control group. We also explored the role of T lymphocytes in controlling the spread of PAO-6 cells, and found the adoptive transfer of lymphocytes significantly controlled the spread of PAO-6 cells, and the protective role could be reversed by CD4 antibody (Fig. 6A-D).

We tested the number of neutrophils $\left(\mathrm{CD} 45^{+} \mathrm{CD} 11 \mathrm{~b}^{+}\right.$ly6 $\left.6 \mathrm{G}^{+}\right)$recruited to the lung in different groups. As shown in Fig. 6E, there were significantly more neutrophils in the lung of immunized mice at $6 \mathrm{~h}$ and $18 \mathrm{~h}$ after challenged by PAO- 6 when compared with that of the unimmunized controls $(p<0.05)$. Immunization could rapidly recruit neutrophils to the lung tissue since the number at $6 \mathrm{~h}$ is similar as that at $18 \mathrm{~h}$ post-infection, which explained the corresponding reduced bacteria load in lung and blood of infected mice early after infection.

Th17 cells and IL-17 were activated by vaccine against LPS heterologous strain. The levels of IL-17 in the supernatants of the immunized T cells were significantly higher than those of control $\mathrm{T}$ cells $(\mathrm{p}<0.05)$. The presence of the anti-CD4 monoclonal antibody during co-culture returned the IL-17 levels as those of the control $\mathrm{T}$ cells, further indicating that $\mathrm{CD} 4^{+} \mathrm{T}$ cells are the predominant source of IL-17 in this system (Fig. 7A).

Mice challenged by PAO- 6 were sacrificed at $6 \mathrm{~h}$ and $18 \mathrm{~h}$ to analyze the specific proliferation of T lymphocytes in the spleen in vivo. The data from Flow Cytometry analysis revealed that the number of $\mathrm{CD} 4^{+} \mathrm{T}$ cells in the group of vaccine-stimulated mice was significantly more than that in the controls at both time points $(\mathrm{p}<0.05)$, while $\mathrm{CD}^{+} \mathrm{T}$ cells proliferation had no significant difference between each groups $(\mathrm{p}>0.05)$ (Fig. $\left.7 \mathrm{~B}\right)$. The number of $\mathrm{CD} 4^{+}$IL- $17^{+}$Th17 cells in the vaccinated mice was significantly higher than in the controls at both time points $(\mathrm{p}<0.05)$ (Fig. 7C), while the number of $\mathrm{CD}^{+} \mathrm{IL}-17^{+} \mathrm{Tc} 17$ cells had no significant difference between each group (data not shown). 

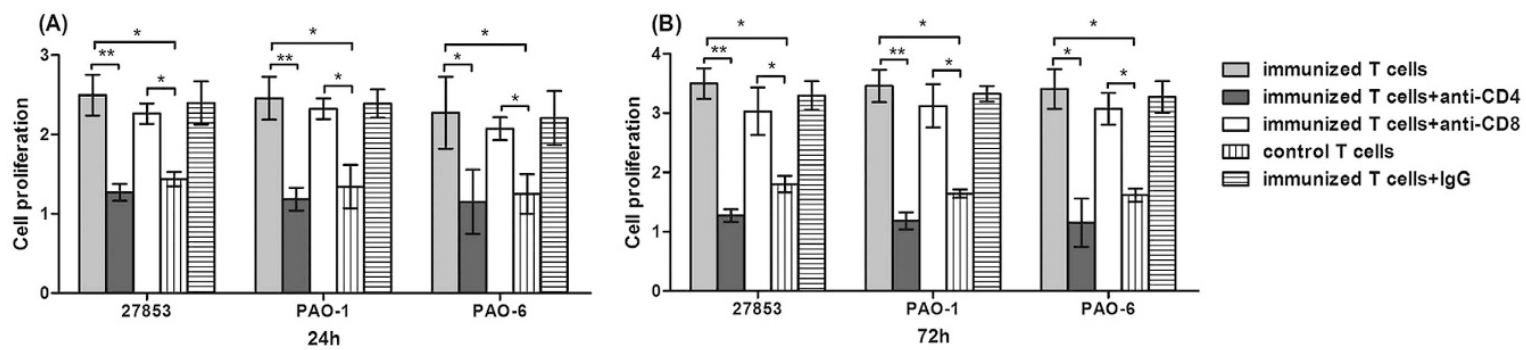

(C)

(D)
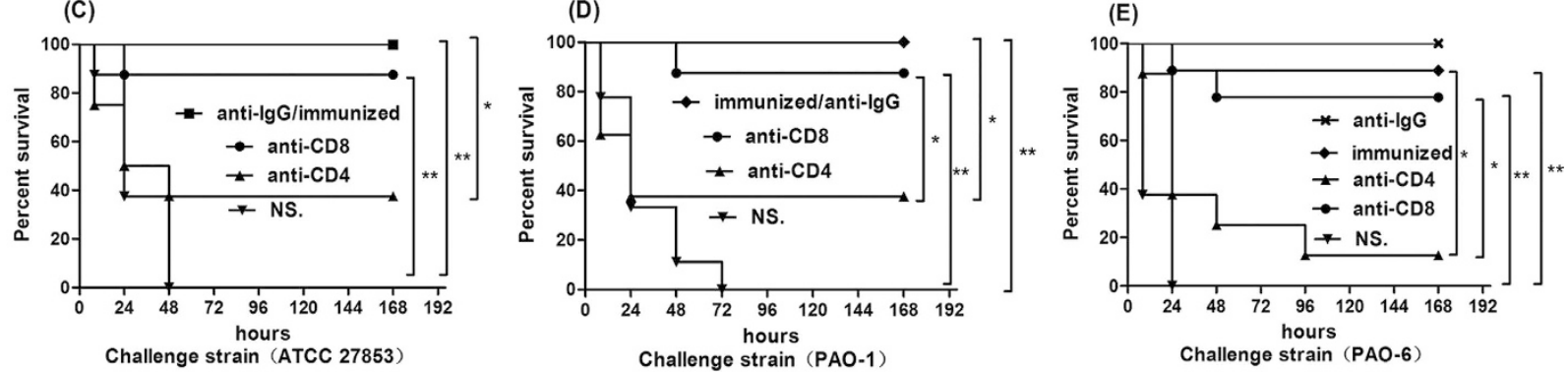

Figure 4. Role of $\mathrm{CD4}^{+} \mathrm{T}$ lymphocytes in vaccine based protection against heterologous or homologous serotype strains. Proliferation of splenic T cells from vaccine immunized mice compared with that of unimmunized mice after the stimulation for $24 \mathrm{~h}(\mathbf{A})$ and $72 \mathrm{~h}(\mathbf{B})$ by heat-killed, whole bacterial cell antigen (ATCC 27853, PAO- and PAO-6). Immunized T cells have higher proliferation than the controls when stimulated by targeted cells at both time points, and the proliferation was significantly decreased by anti-CD4 antibody instead of CD8 antibody. Cells were pooled from three to five mice per group. Results were shown as mean $\pm \mathrm{SD}$ (ANOVA, $\mathrm{n}=3,{ }^{\star} \mathrm{p}<0.05,{ }^{* *} \mathrm{p}<0.01$ ); Mice of control group were immunized with NS, and experimental groups were immunized with escalating doses of $10^{8}, 5 \times 10^{8}, 10^{9}$ and $5 \times 10^{9} \mathrm{CFUs}$ irradiated ATCC 27853 cells every week. At the same time, mice were given either anti-CD4 monoclonal antibody (GK1.5), anti-CD8 monoclonal antibody (clone 2.43) or normal rat IgG to deplete CD4 and CD8 lymphoctyes, and then were challenged with $5 \times 10^{6} \mathrm{CFUs}$ the parental strain ATCC $27853(\mathbf{C}), 5 \times 10^{6} \mathrm{CFUs} \mathrm{homologous}$ serotype PAO-1 (D) and $1 \times 10^{7}$ CFUs heterologous serotype PAO-6 (E). Kaplan-Meier curves were plotted, and depletion of $\mathrm{CD} 4^{+} \mathrm{T}$ lymphocytes showed complete abrogation of the anti-infectious activity with the immunization, whereas depletion of $\mathrm{CD}^{+} \mathrm{T}$ lymphocytes did not affect the protective immunity $(\mathrm{n}=10$, $\left.{ }^{\star} \mathrm{p}<0.05,{ }^{* *} \mathrm{p}<0.01\right)$.

To further explore the role of IL-17 in the vaccine's protective efficacy, we next determined the effects of neutralization of IL-17 prior to lung challenge with the PAO-6 in mice immunized intra-nasally with NS. Control (Fig. 8A) or the vaccine (Fig. 8B). As expected, there was no effect of IL-17 neutralization on survival condition following challenge of the unimmunized mice. However, there was significantly higher mortality in the immunized mice which received anti-IL-17 IgG compared with those given control IgG (Fig. 8A,B). Besides, we also tested the bacterial load of infected lung, and the immunized mice which received anti-IL-17 IgG also had higher level of PAO-6 number than the mice received control IgG, indicating that depletion of IL-17 abrogates vaccine induced protection against LPS heterologous strain challenge (Fig. 8C).

\section{Discussion}

The wide array of virulence factors and the potential of $P$. aeruginosa to infect many different tissues have made it difficult to determine the main and most important microbial antigen targets for effective host immunity ${ }^{19}$. Thus the development of vaccines for $P$. aeruginos $a$ has been hindered by the complexity of the organism's pathogenesis as well as the host immune response ${ }^{10}$. Although multiple . aeruginosa antigens have been studied as vaccine candidates, none of these has demonstrated broad protection against infection with multiple heterologous serogroup strains because they only targeted a single type of bacterial antigen ${ }^{19}$.

Both innate and adaptive immune responses work against bacterial infections ${ }^{20}$, P. aeruginosa is an extracellular pathogen, so humoral, mucosal or systemic opsonizing immunity is most effective preventing bacterial colonization and infection ${ }^{21,22}$. For most vaccines against $P$. aeruginosa infections, serum opsonic antibody directed against the LPS $\mathrm{O}$ antigen has been reported to be the most important immune effector. However, $\mathrm{T}$ lymphocyte responses have also been reported to mediate important protective immunity in individuals with $P$. aeruginosa infection ${ }^{23-25}$. Clinical studies revealed that effective resolution of infection or pathogens clearance is mediated by a combination of neutralizing antibody and inflammatory responses of activated macrophages, neutrophils and immune cells. Therefore, to prevent $P$. aeruginosa infections, an ideal vaccine should comprise a broad range of antigens to elicit both humoral and cellular immunic responses. In our study, significant protection against PAO-6 infection was achieved with the vaccine, and it was not associated with measurable antiserum opsonic killing activity. Our data suggested that the use of X-ray irradiated live-attenuated PA as a vaccine could induce broader, cross-protective cellular and humoral immunologic responses which are not limited to LPS O antigen, and thus expand the spectrum or the potency of protection. 
(A)

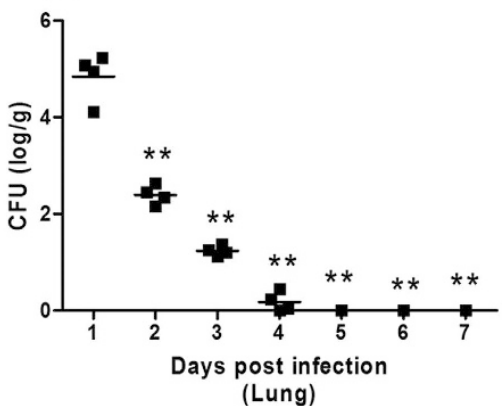

(D)

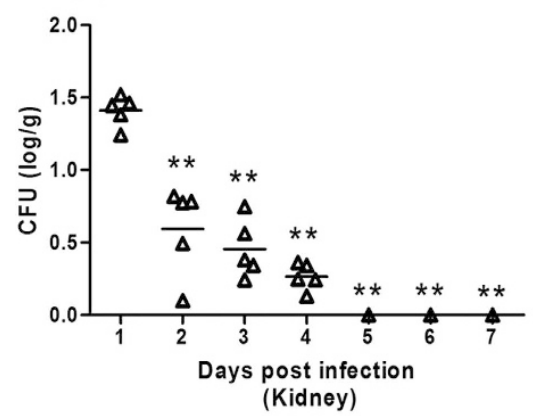

(B)

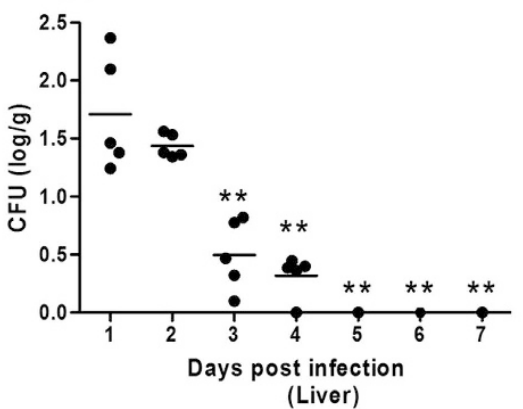

(E)

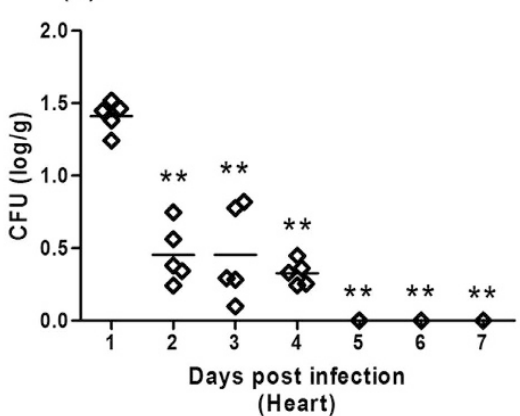

(C)

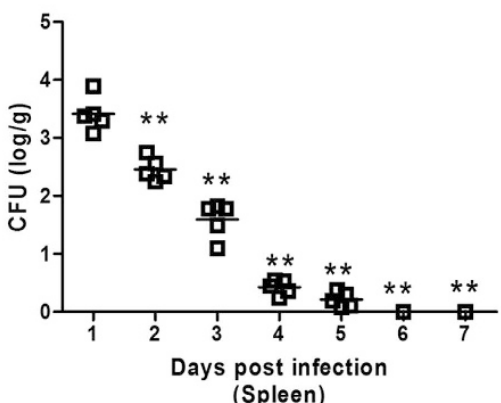

(F)

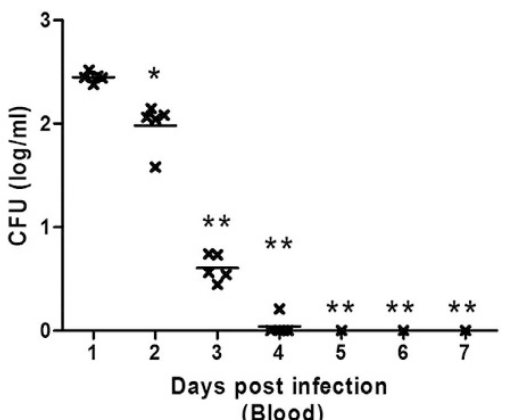

Figure 5. Immunization controls the bacteria spread in main organs and blood of mice after challenged by PAO-6. Immunized C57BL/6 mice received escalating doses of $10^{8}, 5 \times 10^{8}, 10^{9}$, and $5 \times 10^{9} \mathrm{CFUs}$ irradiated ATCC27853 cells intra-nasally every week, and were challenged by $1 \times 10^{7} \mathrm{CFUs}$ PAO- 6 cells. Main organs were collected and tested for bacteria number during the 7 days post challenge (ANOVA, $n=5,{ }^{*} p<0.05,{ }^{* *} \mathrm{p}<0.01$ when compared with PAO-6 number at 24 hours).

We proved that X-ray irradiated P. aeruginosa strain ATCC 27853 vaccine could protect against acute lethal pneumonia caused by LPS-heterologous strain PAO-6. However, the antiserum had only good opsonic killing activity against homologous strain ATCC 27853 and PAO-1. Additionally, the protective effect via serum transfer was only realized when the mice were infected with the homologous strain. T lymphocytes were the effectors against heterologous strain PAO- 6 infection, and in vivo $\mathrm{CD}^{+}{ }^{+} \mathrm{T}$ cell depletion during immunization diminished the vaccine based protection against PAO-6 infection. However, the depletion of CD8 lymphocytes showed partial abrogation of the anti-infection activity when opsonophagocytic killing activity against the strain was absent. Our finding might explain the non effectiveness in reducing the incidence of $P$. aeruginosa infection of a passive administered antibody obtained from vaccinated volunteers from a recent clinical trial ${ }^{26}$. Our study also highlighted the fact that optimal adaptive immunity against the diverse PA strains requires both cellular and humoral effectors. Thus, cooperation of adaptive (CD4 ${ }^{+} \mathrm{T}$ cells and antibodies) and innate (neutrophil and macrophage) immunity can be optimized by vaccination with X-ray irradiated live-attenuated $P$. aeruginosa cells.

Bacterial metabolism has been demonstrated to play a major role in creating proper stimuli required for efficient triggering of protective responses ${ }^{14,27}$. A non-replicating but metabolically active vaccine would ensure that pathogen specific activity are maintained during the infectious process, including the presentation of bacterial antigens and triggering of host immune system. Traditional bacteria inactivation methods, via heat killing or chemical agents, denature the proteins and DNA thus impairing the pathogen's replicating capability and metabolic activity ${ }^{28}$. Alternatively, irradiation provides an effective way to preserve metabolic ability when inactivating the bacteria, since it only causes fragmentation of $\mathrm{DNA}^{17,29}$. After irradiation, a large portion of the genome remains intact, so the bacteria have the potential to express genes in these segments and synthesize or secrete antigens or toxins ${ }^{15,30}$. Irradiation has been used as a method to prevent mammalian cell proliferation without inhibition of cellular activity ${ }^{28}$, the irradiated Toxoplasma gondii was reported to maintain morphology, metabolism, and cell invasion properties ${ }^{31}$. We showed that X-ray irradiated ATCC27853 cells retained the ability to transcribe proteins, maintain relevant targets for immune recognition, and diminish the corresponding replicative competence at the same time. Most importantly, our study suggested that metabolic activity is the key component mediating effective immunity in vaccine exploring. Future modifications to improve metabolic activity might enhance long term protective efficacy of vaccines.

As neutrophils are known to be essential mediators of host defense in the lung against $P$. aeruginosa infection and bacteria clearance, we supposed immunization may increase the number of neutrophils and thus control the spread and proliferation of PAO- 6 bacteria. Of particular interest of our study is that the protective efficacy of vaccine against heterologous serotype PAO- 6 infection coincided with a rapid reduction of bacterial load in lung tissue and blood as well as resulted in increased neutrophil numbers in lung as early as $6 \mathrm{~h}$ after intranasal challenge. Previous study reported that IL-17 from CD4 ${ }^{+}$T cells may induce enhanced production of antimicrobial 


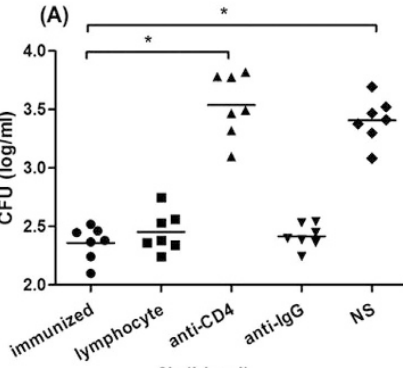

6h (blood)

(c)
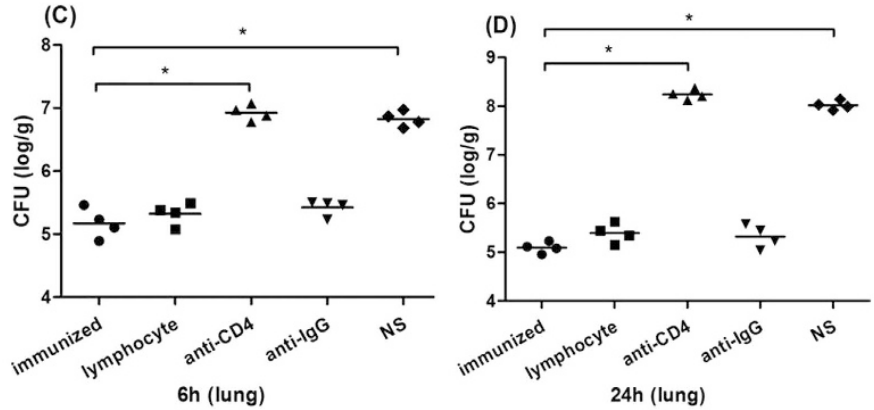

(E)
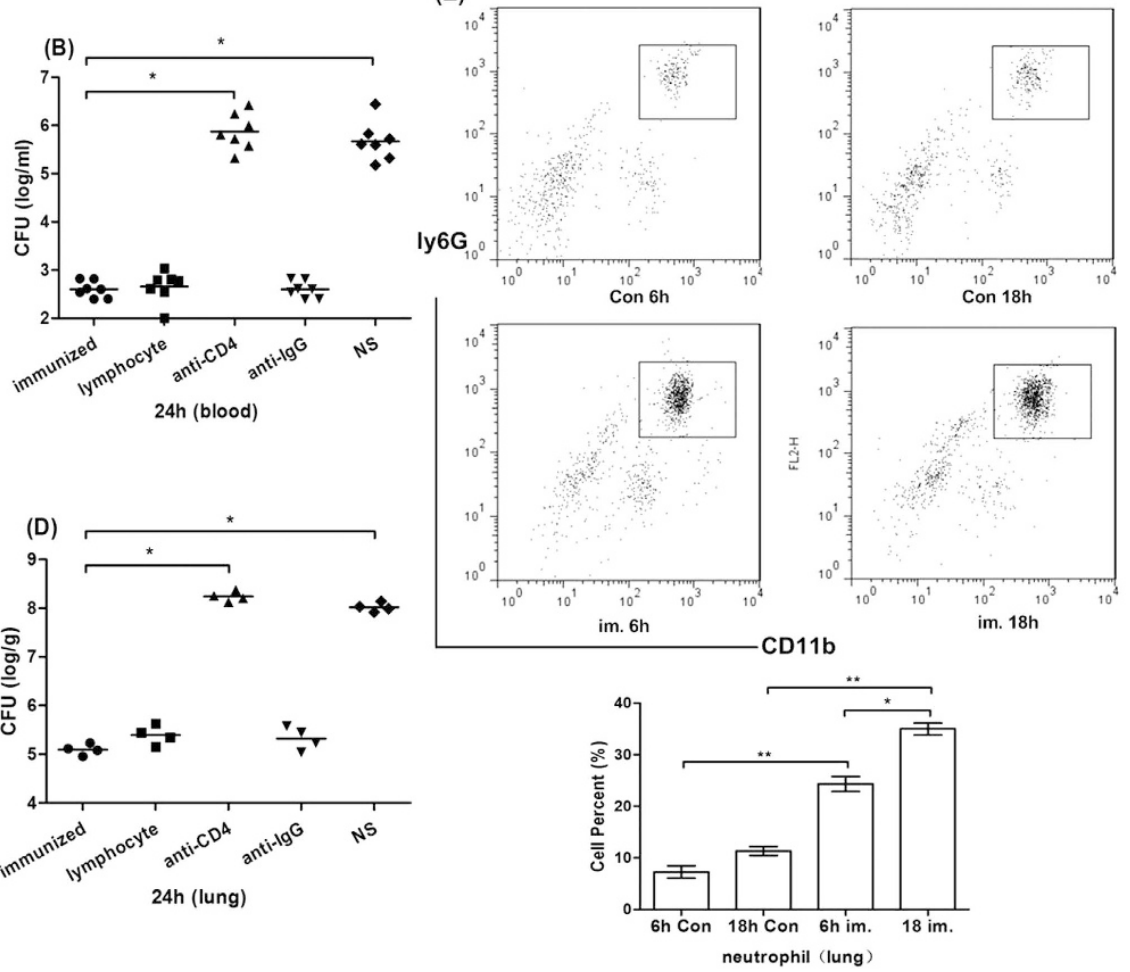

Figure 6. Immunization decreased bacteria load in the lung tissue and blood, and recruited more neutrophils early after heterologous serotype virulent PAO- 6 challenge. Vaccine immunized mice, $\mathrm{T}$ lymphocytes transferred mice, $\mathrm{CD} 4^{+} \mathrm{T}$ lymphocytes depleted mice, IgG control mice and unimmunized mice were all challenged by $1 \times 10^{7} \mathrm{CFUs}$ PAO- 6 cells. At $6 \mathrm{~h}(\mathrm{~A}), 18 \mathrm{~h}(\mathrm{~B})$ after challenge the mice were anaesthetized, and the lung homogenate was collected and plated on agar plates (ANOVA, $n=7,{ }^{*} \mathrm{p}<0.05$, $\left.{ }^{* *} \mathrm{p}<0.01\right)$; At $6 \mathrm{~h}(\mathrm{C}), 18 \mathrm{~h}$ (D) after challenge mice were anaesthetized, and the blood was collected and plated on agar plates $\left(\mathrm{n}=4\right.$, ANOVA, $\left.{ }^{\star} \mathrm{p}<0.05,{ }^{* *} \mathrm{p}<0.01\right)$; (E) At $6 \mathrm{~h}$ and $18 \mathrm{~h}$ after PAO- 6 challenge, lung tissue cells were recovered, firstly gated by CD45 and then stained by CD11b and Ly6G for neutrophil (CD $45^{+}$CD $11 b^{+}$ Ly $6 \mathrm{G}^{+}$) identification. FACS data are presented with the means \pm SD from all experiments for each group Results represent three independent experiments $\left(n=5\right.$, ANOVA, $\left.{ }^{*} p<0.05,{ }^{* *} p<0.01\right)$.

peptides from lung epithelia or by chemokine production from fibroblasts and macrophages, leading to neutrophil recruitment and/or activation ${ }^{32}$, and the subsequent increased phagocytosis of bacteria and enhanced clearance of infection. These findings might be an explaination to the phenomenon that neutropenic patients have a higher incidence of Gram negative bacilli infection, and P. aeruginosais was reported as one of the leading Gram negative causative bacterial agent in neutropenic patients ${ }^{32,33}$.

IL-17 is known to stimulate neutrophil cells recruitment, so we supposed that the recently described Th17 subset of CD4 helper T cells, which secrete the neutrophil attracting cytokine IL-17, might play a role in the rapid recruitment of neutrophils to the lung. In our study, we observed high IL-17 level of immunized T cells after PAO-6 cells antigen stimulation, and high number of CD4 $4^{+} \mathrm{IL}-17^{+}$Th17 cells in the spleen after challenge. Numerous studies have identified a protective role of IL-17 in immunity against various infections, including the infection of intracellular and extracellular bacteria ${ }^{34-36}$. Th17 cells have also been shown to play a critical role in the defense against Klebsiella pneumonia, Pseudomonas aeruginosa in murine models of airway infection, although the bacterial proteins recognized by the Th17 cells in those studies were not fully characterized ${ }^{37-40}$. In our own evaluations of live-attenuated $P$. aeruginosa vaccines, we found that Th17 cell was essential for LPS serogroup independent protection against pneumonia in the absence of opsonophagocytic antibody, it was also associated with rapid recruitment of neutrophils to the airways and the subsequent reduction of bacteria load. These findings indicated that $\mathrm{CD} 4^{+} \mathrm{IL}-17^{+}$Th17 cells mediated immune response may be responsible for the anti-infectious activity afforded by the $\mathrm{X}$-irradiated whole cell vaccine.

\section{Conclusion}

This is an initial but significant step toward understanding the role of X-ray irradiated bacteria vaccine in $P$. aeruginosa infection. Irradiation of whole organisms proves to be a safe and immunogenic vaccine strategy in our preclinical study. In conclusion, our findings might provide a novel strategy of vaccine preparation against $P$. aeruginosa pneumonia, and this novel vaccine indeed obtained a better bacterial clearance effect. Furthermore, this strategy also saves the time and resources of identifying antigenic components for subunit vaccines preparation. The availability and rapidity of irradiation would expedite vaccine production and deployment during epidemic. 


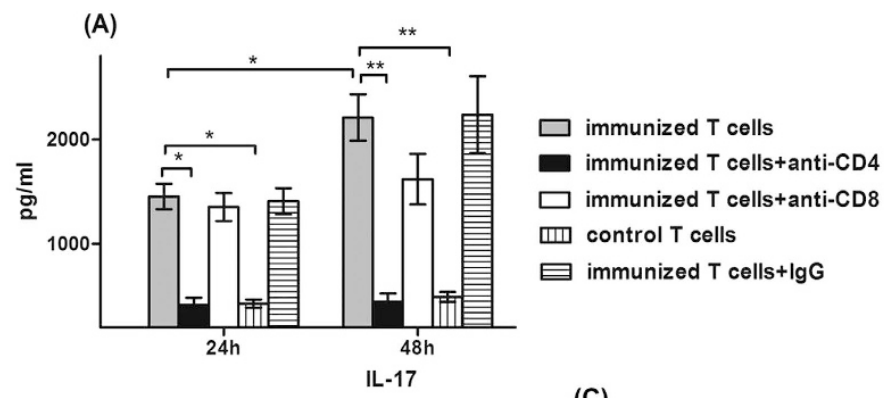

(B)
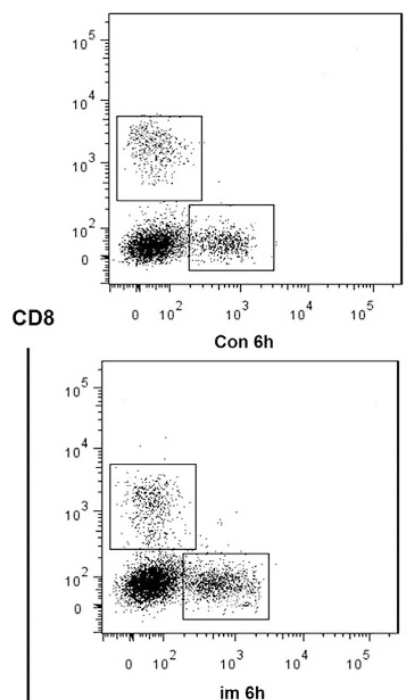

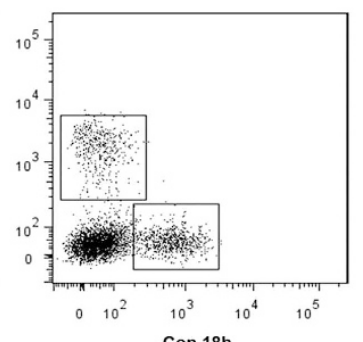

Con $18 \mathrm{~h}$

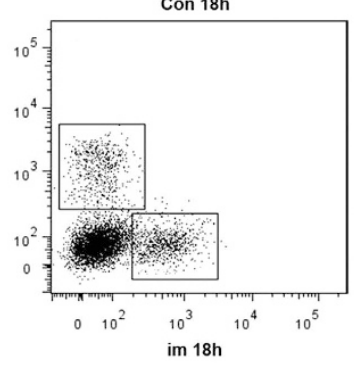

CD4

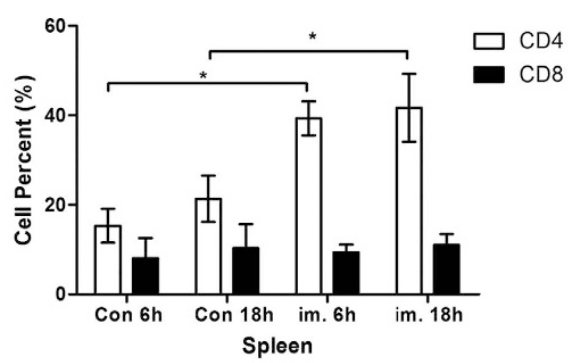

(C)
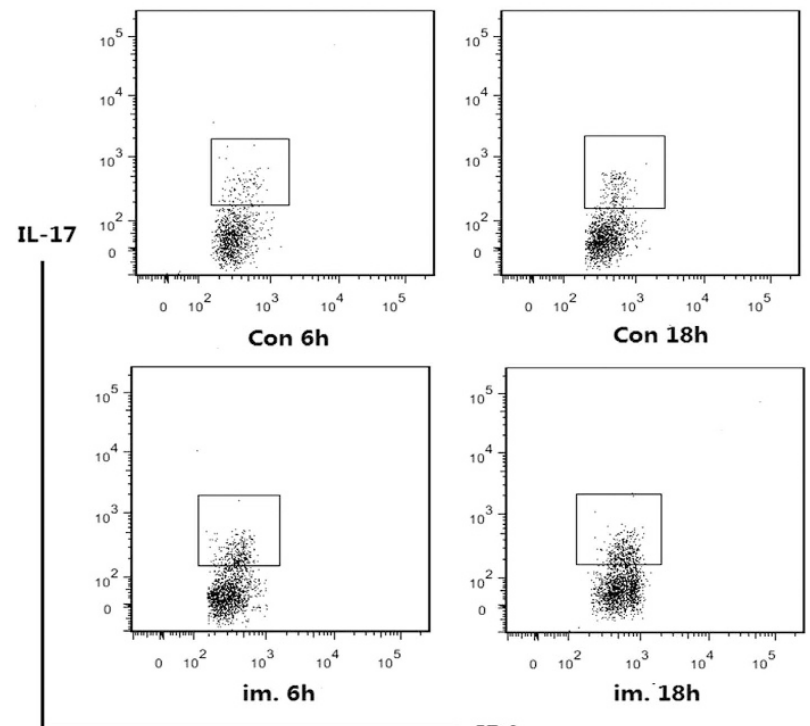

CD4

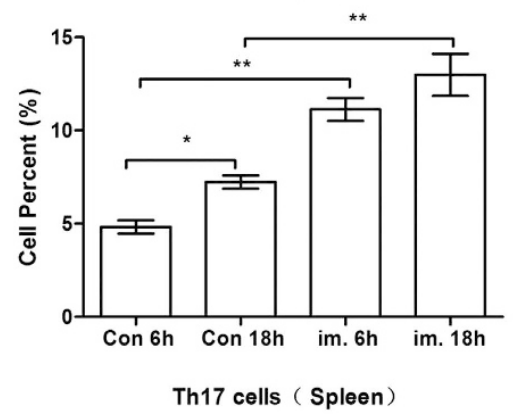

Figure 7. Nasal immunization with irradiated vaccine elicits Th17 cells responses. (A) IL-17 production by splenic T cells isolated from nasal immunized mice and then stimulated for $24 \mathrm{~h}$ and $48 \mathrm{~h}$ in the presence of heat killed whole bacterial cells of PA strain PAO-6 along with irradiated splenocytes. Immunized T cell secreted higher IL-17 than the controls, and IL-17 secretion decreases to baseline when splenic T cells are co-cultured with anti-CD4 monoclonal antibody (clone GK1.5, $1 \mu \mathrm{g} /$ well) at both time points $\left(\mathrm{n}=3\right.$, ANOVA, $\left.{ }^{\star} \mathrm{p}<0.05\right)$; (B) At $6 \mathrm{~h}$ and $18 \mathrm{~h}$ after PAO-6 challenge, spleen cells were recovered, gated by CD4 and CD8 for lymphocytes identification, and immunized mice has significantly higher $\mathrm{CD} 4^{+} \mathrm{T}$ cells compared with controls. FACS data are presented as means $\pm S D$ and represent three independent experiments $\left(n=5\right.$, ANOVA, $\left.{ }^{\star} \mathrm{p}<0.05\right) ;(\mathbf{C})$ At $6 \mathrm{~h}$ and $18 \mathrm{~h}$ after PAO- 6 challenge, spleen cells were recovered, gated by CD4 and IL-17 for lymphocytes identification, and immunized mice has significantly higher $\mathrm{CD} 4^{+} \mathrm{IL}_{-1} 17^{+}$Th 17 cells compared with controls. FACS data are presented as means $\pm S D$ and represent three independent experiments $(n=5$, ANOVA, $\left.{ }^{*} \mathrm{p}<0.05\right)$.

Future studies will be required to establish this strategy as a viable preventable choice against human infection and determine the role of Th17 cells in the resistance to PA infection.

\section{Methods}

Animals and cell lines. All the protocols were performed in accordance with the approved guidelines. Female C57/BL6 mice (all 6-8 weeks of age) were obtained from the Beijing HFK Bioscience Co. Ltd. The mice were maintained at a twelve hours light and night cycle under specific pathogen free (SPF), temperature 
(A)

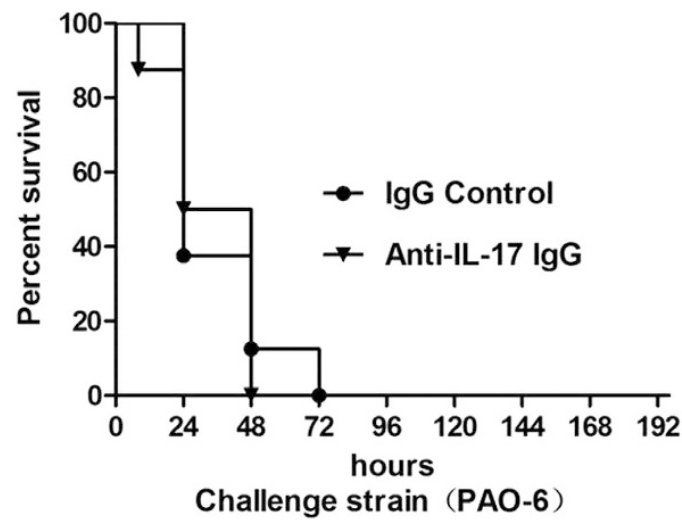

(B)

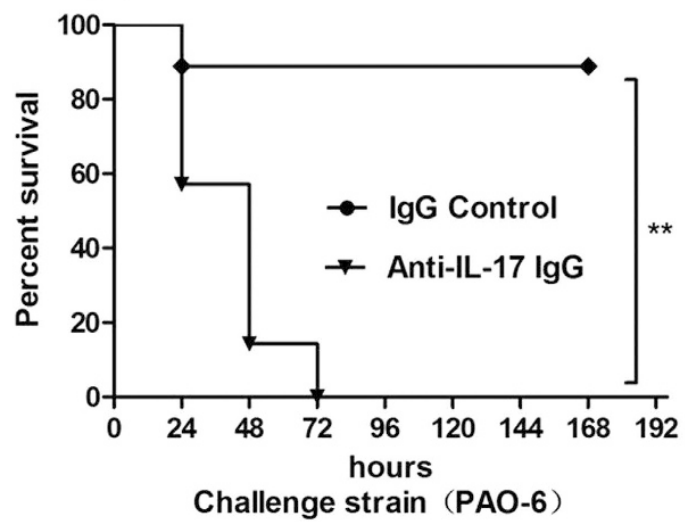

(C)

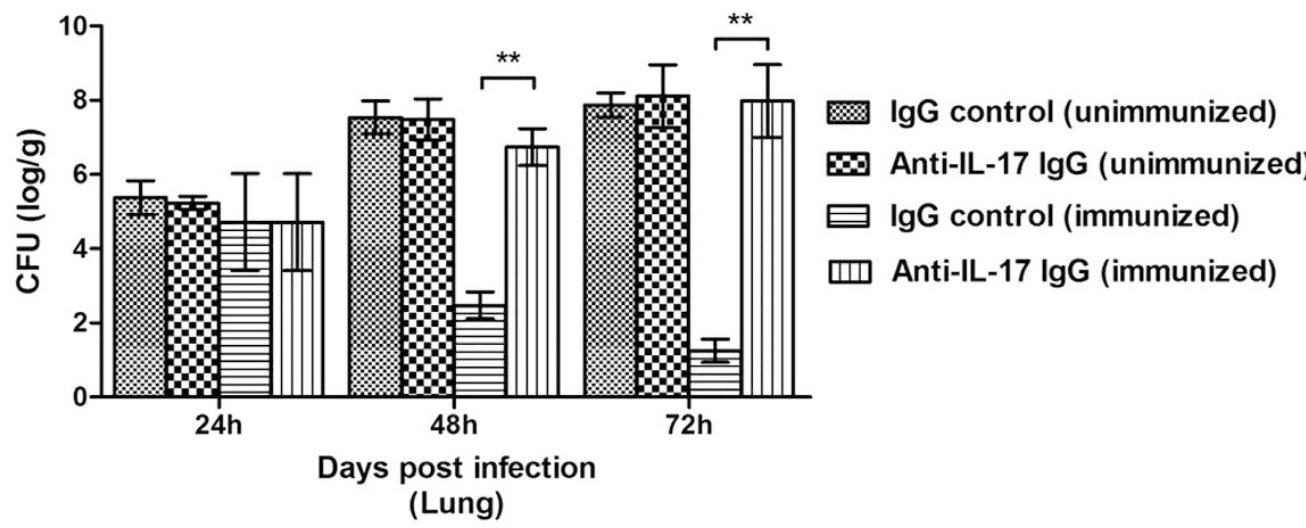

Figure 8. Neutralization of IL-17 diminishes vaccine induced protection against $P$. aeruginosa pneumonia. Survival of unimmunized (A) and immunized (B) mice after administration of IL-17 IgG or control IgG for consecutive 3 days prior to challenge with $5 \times 10^{7} \mathrm{CFUs} \mathrm{PAO}-6(\mathrm{n}=8)$; (C) At 24,48 and 72 hours post infection, the bacteria number of lung were measured in the immunized and control group mice which received either IL-17 IgG or control IgG $\left(n=5\right.$, ANOVA, $\left.{ }^{\star} \mathrm{p}<0.05\right)$.

controlled conditions, and were fed with a standard laboratory diet during the entire experiment. All experimental procedures were approved by the Institutional Animal Care and Use Committee of Sichuan University.

Anti-CD4 mAb hybridoma cell (clone GK1.5, rat IgG), anti-CD8 mAb hybridoma cell (clone 2.43, rat IgG), and bacteria strains (ATCC 27853, PAO-1 and PAO-6) were all purchased from the American Type Culture Collection (Rockville, MD, USA). IL-17 antibody and the control IgG were purchased from Sigma (St. Louis, MO, USA). Hybridoma cell clone 2.43 was cultured in DMEM medium with $10 \%$ fetal bovine serum (FBS), and GK1.5 cultured in Iscove's Modified Dulbecco's (20\% FBS) medium (Invitrogen). P. aeruginosa bacteria were all cultured with Luria-Bertani (LB) medium (Sigma-Aldrich, Shanghai, Trading Co. Ltd).

Determination of bacterial replicate viability and metabolic activity. Pseudomonas aeruginosa ATCC27853 (serotype O2/O5) were grown in LB medium from a single colony for $16-18 \mathrm{~h}$ at $37^{\circ} \mathrm{C}$. The collected bacteria were adjusted to a concentration of $10^{6} / \mathrm{ml}$ and then exposed to various doses of X-ray at escalating intervals from $500 \mathrm{~Gy}$ to $6000 \mathrm{~Gy}$ by a RS2000 Biological X-ray irradiator (Rad Source Technologies, FL, USA) at $220 \mathrm{kV} / 40 \mathrm{~mA}$. Similarly, the collected samples were incubated in a $65^{\circ} \mathrm{C}$ water bath for $0,20,40$, and $60 \mathrm{~min}$ and were kept at $4{ }^{\circ} \mathrm{C}$ until assayed. The replication viability of the bacteria were confirmed by plating serial dilutions on LB agar (BD Biosciences, Heidelberg, Germany), and the colony forming units (CFUs) on the bacterial culture plates were manually counted by a technician blinded to the experimental conditions after incubating for 24 hours.

The metabolic activity was assayed by Alamar Blue (BioSource International, Camarillo, CA), which incorporated a colorimetric growth indicator based on the detection of metabolic activity ${ }^{41,42}$. Briefly, the irradiated or heat incubated samples were firstly washed in normal saline (NS.) and then suspended in LB medium to the original concentration of $10^{6} / \mathrm{ml}$. Then $100 \mu \mathrm{l}$ irradiated suspensions were incubated together with $10 \mu \mathrm{l}$ alamar blue dye for four hours in a 96-well plate. The metabolic activity was determined by detecting the absorbance at $600 \mathrm{~nm}$ and $570 \mathrm{~nm}$, and subtracting $\mathrm{OD}_{600}$ from $\mathrm{OD}_{570}{ }^{42}$. 
Vaccine preparation. Cultured ATCC27853 cells were collected and suspended with NS. to a concentration of $10^{10} / \mathrm{ml}$. One week before immunization, aliquots of the ATCC27853 cells were exposed to 3600 Gy irradiation. The inability of the irradiated bacteria to replicate was confirmed by plating on LB agar after incubating in a bacteria culture incubator for at least three days. The prepared aliquots of vaccine were then stored at $-20^{\circ} \mathrm{C}$ before immunization.

Immunization, infection, and follow up. For the pneumonia model, mice were anesthetized and inoculated intra-nasally with irradiated ATCC27853 cells to further evaluate the protective effect generated by the vaccine $^{43}$. Briefly, mice were immunized by placing $20 \mu$ l of the vaccine inoculums into each nasal $(40 \mu l$ per mouse totally). Escalating doses of $1 \times 10^{8}, 5 \times 10^{8}, 10^{9}$, and $5 \times 10^{9} \mathrm{CFUs}$ were administered at weekly intervals, while the mice in the control group received equal volume of NS.

One week after the fourth immunization, C57/BL6 mice in both groups were intra-nasally challenged with $5 \times 10^{6}$ CFUs equivalents of active ATCC27853, PAO- 1 (serotype O2/O5) or $1 \times 10^{7}$ CFUs PAO-6 (serotype O6). Then, the mice were monitored for seven days' survival rates and bacteria loads after the infection.

In different sets of experiments further explained in the results part, the mice were sacrificed at predetermined time points after immunization or challenge, samples (serum, blood, or organs) were harvested for cytokine levels, bacteria load measurements, lymphocytes/serum extraction or determination for the proportion of neutrophils or Th17 cells by Flow Cytometry. The decision to sacrifice mice was made before the experiment was started.

Adoptive transfer or depletion of spleen lymphocytes (serum) in vivo. Preparation of spleen lymphocytes and serum was performed according to the method described previously ${ }^{44}$. Briefly, the immunized mice were sacrificed a week after the fourth immunization, blood samples were collected to coagulate and then centrifuged at $1000 \mathrm{~g}$ for $20 \mathrm{~min}$ to isolate the serum. Mice spleen was harvested at a sterilized condition, cell suspensions were generated through a $70 \mu$ m nylon mesh filter (BD Biosciences), and lymphocytes were enriched by specific separation medium and density gradient centrifugation.

For Adoptive transfer of antiserum or lymphocytes experiment, $1 \times 10^{7}$ lymphocytes or $300 \mu \mathrm{l}$ serum were adoptively transferred intravenously $12 \mathrm{~h}$ before and after C57BL/6 mice were challenged with live virulent ATCC 27853, PAO-1, or PAO-6 cells. For lymphocytes depletion experiment, immune cell subsets were depleted as described previously ${ }^{44}$. Mice were injected intraperitoneally with $500 \mu \mathrm{g}$ monoclonal antibodies against CD8, CD4, or the isotype control IgG antibody one day before the first immunization, and then twice a week for four weeks until the immunization accomplished. Then the immunized mice, $\mathrm{CD} 4^{+} \mathrm{T}$ lymphocytes depleted mice, $\mathrm{CD} 8^{+} \mathrm{T}$ lymphocytes depleted mice, and the unimmunized mice were all challenged with live ATCC 27853, PAO-1, or PAO-6 cells, and then were monitored for seven days survival rates after intra-nasal infection. Similarly, IL-17 depletion studies were done using anti-IL-17 IgG (1 mg i.p.) or control IgG for consecutive 3 days before the mice were challenged by PAO- 6 cells.

Opsonophagocytic assays. Standard methods were employed to test the antibody dependent opsonophagocytic killing ability of antiserum isolated from the immunized mice ${ }^{45}$. Briefly, $2 \times 10^{6}$ cells polymorphonuclear leukocytes (PMNs) from human volunteers, $5 \times 10^{5}$ CFUs PA targeted strain (ATCC 27853, PAO-1, or PAO-6), and $200 \mu \mathrm{l}$ anti-sera were mixed in a sterile micro-centrifuge tube and incubated for $4 \mathrm{~h}$ at $220 \mathrm{rpm} / \mathrm{min}$. The anti-sera were collected and pooled after the fourth immunization as mentioned above. Control group contained serum isolated from the unimmunized mice, and tubes with serum isolated from unimmunized mice but without PMNs served as additional negative controls to help distinguish killing from agglutination ${ }^{46}$.

After incubation, each well was subjected to serial log-fold dilutions to determine the bacterial CFUs, and the decreased percent of bacterial CFUs in the experimental tube compared to that in tubes incubated with unimmunized sera was calculated as the opsonophagocytic activity. Assays were performed in three times for each sample. Under routine conditions, killing of above $50 \%$ is considered biologically significant and we can classify the serum as positive for opsonophagocytic killing activity.

T cell proliferation and cytokine measurements. For proliferation experiments ${ }^{47}$, each well of a 96 -well plate was seeded with $1 \times 10^{5} \mathrm{~T}$ cells isolated from immunized mice, $1 \times 10^{5}$ irradiated $(1500 \mathrm{rad})$ splenocytes isolated from normal mice as antigen presenting cells (APCs), and $1 \times 10^{6}$ heat-killed bacteria (ATCC 27853, PAO-1, or PAO-6) as antigen, while additional groups contained $1 \mu \mathrm{g}$ per well anti-CD4, anti-CD8, or rat IgG isotype (BD Biosciences) antibody to identify the specific proliferation ability of different group lymphocytes. The well of control group contained $\mathrm{T}$ cells isolated from the unimmunized mice, and the cells were all cultured by RPMI 1640 containing 10\% heat-inactivated FBS. The killed bacteria were verified by the absence of growth on LB agar.

At $24 \mathrm{~h}$ and $72 \mathrm{~h}$ after incubation, T lymphocyte proliferation in above different groups was assessed using Cell Counting Kit-8 (CCK-8) assay according to the manufacturer's protocol. At the same time, the supernatants in each well were collected for testing IL-17 cytokine levels using the commercial mice ELISA kit (Sigma-Aldrich, Shanghai, China).

Quantification of bacterial counts in blood and main organs. The immunized and control group mice were sacrificed by dislocation of lumber bar at predetermined time after the induction of intranasal infection by PAO- 6 cells. Blood (bled from the retro-orbital sinuses) and organ tissue homogenate were harvested under sterile conditions and subjected to serial log-fold dilutions using sterilized NS. The dilutions from all samples were then plated onto sheep blood agar plates (BD Biosciences, Heidelberg, Germany). After overnight incubation, the CFUs of the bacterial culture plates were manually counted by a technician blinded to the experimental conditions. Data were expressed as CFUs per mL blood or per g of lung tissue. 
Flow cytometry. The immunized and control animals were sacrificed by dislocation of lumber bar at $6 \mathrm{~h}$ and $18 \mathrm{~h}$ after challenged with PAO- 6 cells. Spleen and lung tissue single cell suspensions were harvested by method described previously ${ }^{48}$. Lung cells were incubated for $30 \mathrm{~min}$ on ice with $1 \mu \mathrm{L}$ of relevant Abs (CD45-PE, CD11b-APC, and ly6G-FITC) or matched isotype control Abs for detection of neutrophils. Intracellular cytokine staining was performed using a kit from BD Biosciences according to the manufacturers' instructions. Spleen cells of immunized or control mice were stained with CD4-APC or CD8-Alex Flour 488 mice antibody, followed by fixation and permeabilization and then were stained with PE-labeled IL-17 antibody. Antibodies and appropriate isotype controls were also obtained from BD Biosciences. Flow cytometry data were acquired by a FACS Calibur flow cytometer (BD Biosciences) and analyzed with FLOW JO software 7.6 (Tree Star Inc., Ashland, OR).

Statistical analysis. All data were analyzed using GRAPHPAD PRISM software (GraphPad, San Diego, CA). Data were analyzed using ANOVA (multiple groups), and multiple comparisons between the groups were performed using Newman-Keuls method after ANOVA. Survival data were plotted using Kaplan-Meier curves and analyzed by the log-rank test. For measurements of bacterial CFUs, groups were compared using a nonparametric Mann-Whitney U-test. $\mathrm{p}<0.05$ was considered to be statistically significant for all experiments. All values were presented as the mean $\pm \mathrm{SD}$, with the exception of bacterial counts, for which median values were designated.

\section{References}

1. Spencer, R. C. Predominant pathogens found in the European Prevalence of Infection in Intensive Care Study. Eur J Clin Microbiol Infect Dis 15, 281-285 (1996).

2. Velasco, E., Thuler, L. C., Martins, C. A., Dias, L. M. \& Goncalves, V. M. Nosocomial infections in an oncology intensive care unit. Am J Infect Control 25, 458-462 (1997).

3. Sun, H. Y., Fujitani, S., Quintiliani, R. \& Yu, V. L. Pneumonia due to Pseudomonas aeruginosa: part II: antimicrobial resistance, pharmacodynamic concepts, and antibiotic therapy. Chest 139, 1172-1185 (2011).

4. Breidenstein, E. B., de la Fuente-Nunez, C. \& Hancock, R. E. Pseudomonas aeruginosa: all roads lead to resistance. Trends Microbiol 19, 419-426 (2011)

5. Ben Haj Khalifa, A., Moissenet, D., Vu Thien, H. \& Khedher, M. Virulence factors in Pseudomonas aeruginosa: mechanisms and modes of regulation. Ann Biol Clin 69, 393-403 (2011).

6. Bruderer, U. et al. Affinity constants of naturally acquired and vaccine-induced anti-Pseudomonas aeruginosa antibodies in healthy adults and cystic fibrosis patients. J Infect Dis 166, 344-349 (1992).

7. Ciofu, O., Petersen, T. D., Jensen, P. \& Hoiby, N. Avidity of anti-P aeruginosa antibodies during chronic infection in patients with cystic fibrosis. Thorax 54, 141-144 (1999).

8. Sharma, A., Krause, A. \& Worgall, S. Recent developments for Pseudomonas vaccines. Hum Vaccin 7, 999-1011 (2011).

9. Doring, G. \& Pier, G. B. Vaccines and immunotherapy against Pseudomonas aeruginosa. Vaccine 26, 1011-1024 (2008).

10. Holder, I. A. Pseudomonas immunotherapy: a historical overview. Vaccine 22, 831-839 (2004).

11. Sedlak-Weinstein, E., Cripps, A. W., Kyd, J. M. \& Foxwell, A. R. Pseudomonas aeruginosa: the potential to immunise against infection. Expert Opin Biol Ther 5, 967-982 (2005).

12. Buret, A., Dunkley, M., Clancy, R. L. \& Cripps, A. W.. Effector mechanisms of intestinally induced immunity to Pseudomonas aeruginosa in the rat lung: role of neutrophils and leukotriene B4. Infect Immun 61, 671-679 (1993).

13. Rappuoli, R., Mandl, C. W., Black, S. \& De Gregorio, E. Vaccines for the twenty-first century society. Nat Rev Immunol 11, 865-872 (2011).

14. Skoble, J. et al. Killed but metabolically active Bacillus anthracis vaccines induce broad and protective immunity against anthrax. Infect Immun 77, 1649-1663 (2009).

15. Sanakkayala, N. et al. Induction of antigen-specific Th1-type immune responses by gamma-irradiated recombinant Brucella abortus RB51. Clin Diagn Lab Immunol 12, 1429-1436 (2005).

16. Alsharifi, M. et al. Intranasal flu vaccine protective against seasonal and H5N1 avian influenza infections. PLoS One 4, e5336 (2009).

17. Datta, S. K. et al. Vaccination with irradiated Listeria induces protective T cell immunity. Immunity 25, 143-152 (2006).

18. Quan, F. S. et al. Resistance to reinfection in rats induced by irradiated metacercariae of Clonorchis sinensis. Mem Inst Oswaldo Cruz 100, 549-554 (2005).

19. Priebe, G. P. \& Goldberg, J. B. Vaccines for Pseudomonas aeruginosa: a long and winding road. Expert Rev Vaccines 13, 507-519 (2014).

20. Napier, R. J., Adams, E. J., Gold, M. C. \& Lewinsohn, D. M. The Role of Mucosal Associated Invariant T Cells in Antimicrobial Immunity. Front Immunol 6, 344 (2015)

21. Tummler, B., Wiehlmann, L., Klockgether, J. \& Cramer, N. Advances in understanding Pseudomonas. F1000Prime Rep 6, 9 (2014).

22. Mesaros, N. et al. Pseudomonas aeruginosa: resistance and therapeutic options at the turn of the new millennium. Clin Microbiol Infect 13, 560-578 (2007).

23. Dunkley, M. L., Clancy, R. L. \& Cripps, A. W. A role for CD4+ T cells from orally immunized rats in enhanced clearance of Pseudomonas aeruginosa from the lung. Immunology 83, 362-369 (1994).

24. Dunkley, M. L., Cripps, A. W., Reinbott, P. W. \& Clancy, R. L. Immunity to respiratory Pseudomonas aeruginosa infection: the role of gut-derived Thelper cells and immune serum. Adv Exp Med Biol 371B, 771-775 (1995).

25. Stevenson, M. M., Kondratieva, T. K., Apt, A. S., Tam, M. F. \& Skamene, E. In vitro and in vivo T cell responses in mice during bronchopulmonary infection with mucoid Pseudomonas aeruginosa. Clin Exp Immunol 99, 98-105 (1995).

26. Bumann, D. et al. Systemic, nasal and oral live vaccines against Pseudomonas aeruginosa: a clinical trial of immunogenicity in lower airways of human volunteers. Vaccine 28, 707-713 (2010).

27. Bruhn, K. W. et al. Killed but metabolically active Leishmania infantum as a novel whole-cell vaccine for visceral leishmaniasis. Clin Vaccine Immunol 19, 490-498 (2012).

28. Soiffer, R. et al. Vaccination with irradiated, autologous melanoma cells engineered to secrete granulocyte-macrophage colonystimulating factor by adenoviral-mediated gene transfer augments antitumor immunity in patients with metastatic melanoma. J Clin Oncol 21, 3343-3350 (2003).

29. Daly, M. J. Death by protein damage in irradiated cells. DNA Repair (Amst) 11, 12-21 (2012).

30. Trampuz, A., Piper, K. E., Steckelberg, J. M. \& Patel, R. Effect of gamma irradiation on viability and DNA of Staphylococcus epidermidis and Escherichia coli. J Med Microbiol 55, 1271-1275 (2006).

31. Hiramoto, R. M., Galisteo, A. J., do Nascimento, N. \& de Andrade, H. F., Jr. 200 Gy sterilised Toxoplasma gondii tachyzoites maintain metabolic functions and mammalian cell invasion, eliciting cellular immunity and cytokine response similar to natural infection in mice. Vaccine 20, 2072-2081 (2002) 
32. Shahrara, S. et al. IL-17-mediated monocyte migration occurs partially through CC chemokine ligand $2 /$ monocyte chemoattractant protein-1 induction. J Immunol 184, 4479-4487 (2010).

33. Marin, M. et al. Bloodstream infections in neutropenic patients with cancer: differences between patients with haematological malignancies and solid tumours. J Infect 69, 417-423 (2014).

34. Ye, P. et al. Requirement of interleukin 17 receptor signaling for lung CXC chemokine and granulocyte colony-stimulating factor expression, neutrophil recruitment, and host defense. J Exp Med 194, 519-527 (2001)

35. Zhou, X. et al. Critical role of the interleukin-17/interleukin-17 receptor axis in regulating host susceptibility to respiratory infection with Chlamydia species. Infect Immun 77, 5059-5070 (2009).

36. Wu, Q. et al. IL-23-dependent IL-17 production is essential in neutrophil recruitment and activity in mouse lung defense against respiratory Mycoplasma pneumoniae infection. Microbes Infect 9, 78-86 (2007).

37. Ye, P. et al. Interleukin-17 and lung host defense against Klebsiella pneumoniae infection. Am J Respir Cell Mol Biol 25, 335-340 (2001).

38. Kudva, A. et al. Influenza A inhibits Th17-mediated host defense against bacterial pneumonia in mice. J Immunol 186, 1666-1674 (2011).

39. Zielinski, C. E. et al. Pathogen-induced human TH17 cells produce IFN-gamma or IL-10 and are regulated by IL-1beta. Nature 484, 514-518 (2012)

40. Priebe, G. P. et al. IL-17 is a critical component of vaccine-induced protection against lung infection by lipopolysaccharideheterologous strains of Pseudomonas aeruginosa. J Immunol 181, 4965-4975 (2008).

41. Moustafa, D., Garg, V. K., Jain, N., Sriranganathan, N. \& Vemulapalli, R. Immunization of mice with gamma-irradiated Brucella neotomae and its recombinant strains induces protection against virulent B. abortus, B. melitensis, and B. suis challenge. Vaccine 29, 784-794 (2011)

42. Magnani, D. M., Harms, J. S., Durward, M. A. \& Splitter, G. A. Nondividing but metabolically active gamma-irradiated Brucella melitensis is protective against virulent B. melitensis challenge in mice. Infect Immun 77, 5181-5189 (2009).

43. Bansal, S. \& Chhibber, S. Phytochemical-induced reduction of pulmonary inflammation during Klebsiella pneumoniae lung infection in mice. J Infect Dev Ctries 8, 838-844 (2014).

44. $\mathrm{Lu}$, Y. et al. Immunogene therapy of tumors with vaccine based on xenogeneic epidermal growth factor receptor. J Immunol 170, 3162-3170 (2003).

45. Priebe, G. P., Meluleni, G. J., Coleman, F. T., Goldberg, J. B. \& Pier, G. B. Protection against fatal Pseudomonas aeruginosa pneumonia in mice after nasal immunization with a live, attenuated aroA deletion mutant. Infect Immun 71, 1453-1461 (2003).

46. Kamei, A., Coutinho-Sledge, Y. S., Goldberg, J. B., Priebe, G. P. \& Pier, G. B. Mucosal vaccination with a multivalent, live-attenuated vaccine induces multifactorial immunity against Pseudomonas aeruginosa acute lung infection. Infect Immun 79, 1289-1299 (2011).

47. Masopust, D., Vezys, V., Marzo, A. L. \& Lefrancois, L. Preferential localization of effector memory cells in nonlymphoid tissue. Science 291, 2413-2417 (2001).

48. Wei, Y. Q. et al. Immunotherapy of tumors with xenogeneic endothelial cells as a vaccine. Nat Med 6, 1160-1166 (2000).

\section{Acknowledgements}

This work was supported by the National Natural Science Foundation of China (No. 81123003); and the National Basic Research Program of China (No. 2010CB529900), This work was also financially supported by National Natural Science Foundation of China (NSFC:81301961). We thank Dr. Binglan Zhang from west china hospital for her help in preparing figures, and we thank Dr. Tomas Lie from University of Washington Department of Microbiology for his contribution in English language editing.

\section{Author Contributions}

L.Y., W.Z., L.X. and W.Y. carried out the study design, performed experiment and wrote the main manuscript, P.B. and T.J. prepared figures and performed part of the in vivo experiment. All authors reviewed the manuscript.

\section{Additional Information}

Supplementary information accompanies this paper at http://www.nature.com/srep

Competing financial interests: The authors declare no competing financial interests.

How to cite this article: Li, Y. et al. X-ray Irradiated Vaccine Confers protection against Pneumonia caused by Pseudomonas Aeruginosa. Sci. Rep. 6, 18823; doi: 10.1038/srep18823 (2016).

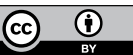

This work is licensed under a Creative Commons Attribution 4.0 International License. The images or other third party material in this article are included in the article's Creative Commons license, unless indicated otherwise in the credit line; if the material is not included under the Creative Commons license, users will need to obtain permission from the license holder to reproduce the material. To view a copy of this license, visit http://creativecommons.org/licenses/by/4.0/ 